\title{
The role of tactual information in the recall of concrete objects
}

\author{
JOHN T. E. RICHARDSON, HEATHER M. AINSLEY, SARAH COPSEY, \\ and STUART A. WATKINS \\ Brunel University, Uxbridge, Middlesex UB8 3PH, England
}

\begin{abstract}
Subjects who were instructed to handle a set of 16 objects were subsequently more efficient in recalling those objects than were subjects who observed the objects without touching them. This suggests that tactual information may survive perception and be encoded in long-term memory.
\end{abstract}

There has been relatively little investigation of the role of tactual information in episodic memory. This may be because of an assumption that normal, sighted individuals are capable of only gross tactual discrimination and that any tactual memory trace that might result is subject to rapid decay (Sullivan \& Turvey, 1972). However, recent evidence has shown that both blind and blindfolded normal subjects are capable of relatively fine tactual discrimination (Magee \& Kennedy, 1980), and it has also been suggested that tactual stimulation may give rise to nonverbal memory traces of a relatively long-term nature (Gilson \& Baddeley, 1969). Millar (1975) showed that the short-term serial recall of concrete objects was affected by both tactual and phonemic similarity in both blind and blindfolded normal children. Errors on tactually similar sequences of objects could not be attributed to semantic confusions. She concluded that tactual information can survive the presentation of stimulus material and may affect its subsequent recall. Given that tactual coding may be employed when only tactual information is available, the question arises whether this form of encoding may also be employed when the stimulus objects are presented visually. The following experiment was designed to test the hypothesis that the availability of tactual information will increase performance in the long-term free recall of concrete objects.

\section{METHOD}

Sixteen familiar objects were arranged on a table in an unsystematic fashion and were covered by a cloth. They were exposed to each subject for $90 \mathrm{sec}$, and the cloth was replaced. The subjects then carried out an irrelevant task for $2 \mathrm{~min}$, in which they had to delete any item in an array of randomly generated two-digit numbers that was divisible by three or four. Finally, each subject was allowed 2 min to recall the objects in any order on a prepared response sheet. The 16 objects (and acceptable alternative responses) were as follows: comb, egg cup, key, mirror, nail brush (brush, scrubber), nail scissors (scissors), nail varnish (nail polish), pen (biro), pencil, pendant (chain,

Requests for reprints should be sent to J. T. E. Richardson, Department of Psychology, Brunel University, Uxbridge, Middlesex UB8 3PH, England. locket, necklace), rubber (eraser), screw (nail, bolt), shoe lace (boot lace, lace), stone (rock), teaspoon (spoon), 2-pence piece (penny, 2 p, 2-p piece).

Thirty-six students applying for admission to the psychology honors degree course at Brunel University volunteered to participate in this experiment, and they were tested individually. Twenty subjects were tested by a male experimenter (S.W.), and 16 were tested by a female experimenter (H.A.). Half of the subjects tested by each experimenter were male, and half were female. Independent of this, half of the subjects tested by each experimenter were instructed to memorize the objects but not to touch any of them (nontouch condition); the other half were instructed to memorize the objects and to handle all of them (touch condition). All of the subjects were given standard free recall instructions, except that, following a signal from the experimenter, they were to draw a line under the last item recalled to indicate successive 30 -sec intervals during the recall period.

\section{RESULTS}

The mean cumulative numbers of items recalled over the four $30-\mathrm{sec}$ intervals of the recall period by the subjects in the nontouch condition were $7.44(46.5 \%)$, 10.11 (63.2\%), 11.39 (71.2\%), and 11.61 (72.6\%). The mean cumulative numbers of items recalled by the subjects in the touch condition were 8.78 (54.9\%), $11.83(74.0 \%), 12.83(80.2 \%)$, and $13.33(83.3 \%)$. It is apparent that the subjects in the touch condition produced superior performance throughout the recall period.

The two conditions were compared by means of an analysis of variance on the total number of correct items given by each subject. The analysis included as factors the sex of the subject and the sex of the experimenter. An unweighted-means solution was employed to evaluate the latter effect. The difference between the two conditions was highly significant $[F(1,28)=10.49$, $\mathrm{p}<.005]$, but no other term in the analysis even approached statistical significance.

\section{DISCUSSION}

This experiment has demonstrated a substantial and highly significant improvement in the long-term recall of concrete objects resulting from the availability of tactual information. 
It has therefore supported the suggestion of Millar (1975) that tactual information can outlast perception and affect recall, but it has also extended the range of experimental situations in which such information is known to be important. Tactual encoding in human memory may be employed not merely when the stimulus objects are available only to the sense of touch, but also when they are presented visually.

From a theoretical point of view, it is perfectly easy to interpret the present findings on the grounds that objects that are encoded in two different modes will be recalled more efficiently than those that are encoded only in a single mode. Nevertheless, the question arises as to whether the opportunity for tactual exploration in this experiment produced a form of long-term coding that was specifically tactual in nature. Several investigators have argued that adults recode tactual information into visual images (Attneave \& Benson, 1969; Paivio, 1971, p. 149; Sullivan \& Turvey, 1974). On the other hand, Millar (1974) suggested that the tactual recognition of nonsense shapes by blind and sighted children might be mediated by verbal recoding. In her experiments with familiar concrete objects, Millar (1975) found that the effect of phonemic similarity upon serial recall increased with the subject's verbal memory span, whereas the effect of tactual similarity showed the opposite trend. This suggested that tactual information becomes less important as the subjects increase in their ability to use verbal codes.

However, in the present context, it is difficult to see how either visual or verbal recoding might produce the substantial improvement in memory performance that was actually obtained as a result of the availability of tactual information. The objects were presented in clear view for a substantial period of time; moreover, they were all highly familiar and could be easily named by the type of subject employed. Since the subjects had ample opportunity to encode the stimuli both visually and verbally without the opportunity for tactual exploration, any visual or verbal recoding that might have resulted from such exploration would have been formally redundant. It is therefore much more reasonable to suppose that the improvement in memory performance that resulted from tactual stimulation in this experiment was mediated by a form of coding in long-term memory that was specifically tactual in nature.

\section{REFERENCES}

Attneave, F., \& Benson, B. Spatial coding of tactual stimulation. Journal of Experimental Psychology, 1959, 81, 216-222.

Gilson, E., \& Baddeley, A. D. Tactile short-term memory. Quarterly Journal of Experimental Psychology, 1969, 21, 180-184.

MAGEe, L. E., \& KenNEDY, J. M. Exploring pictures tactually. Nature, 1980, 283, 287-288.

Millak, S. Tactile short-term memory by blind and sighted children. British Journal of Psychology, 1974, 65, 253-263.

Millar, S. Effects of phonological and tactual similarity on serial object recall by blind and sighted children. Cortex, 1975, 11, 170-180.

Paivio, A. Imagery and verbal processes. New York: Holt, Rinehart, \& Winston, 1971.

Sullivan, E. V., \& Turvey, M. T. Short-term retention of tactile stimulation. Quarterly Journal of Experimental Psychology, 1972, 24, 253-261.

Sullivan, E. V., \& Turvey, M. T. On the short-term recognition of serial tactile stimuli. Memory \& Cognition, 1974, 2, 601-606.

(Received for publication April 20, 1980.) 